\title{
La intervención imperial en las capitales conventuales de Hispania*
}

Juan Manuel Abascal Palazón

Universidad de Alicante

juan.abascal@ua.es

Fecha recepción 22.02.2016 / Fecha aceptación 01.04.2016

\section{Resumen}

Las noticias sobre la presencia de los emperadores romanos en las grandes ciudades de la Península Ibérica son muy escasas. Sin embargo mediante la organización conventual, la extensión de la iconografía oficial, las mutaciones en el ámbito religioso, la extensión de la indulgentia del Princeps en el trato individual con cada comunidad y la generalización de los modelos urbanísticos, hubo una presencia real, casi constante en cada ciudad, del emperador y de su entorno. Esa intervención se haría evidente a partir del siglo II d. C. con el nombramiento de los curatores. El balance de los testimonios conocidos muestra que la condición de sede conventual no fue determinante para una mayor o menor relación con el emperador.

\section{Palabras clave}

Emperador, indulgentia, hábito epigráfico, iconografía, Hispania.

\section{Abstract}

The presence of Roman emperors in the major cities of the Iberian Peninsula receives only very rare coverage. In every city, however, there was an almost constant physical presence of the emperor and his environment through the organization of the conventus iuridici, the use of official iconography, mutations in the religious sphere, the extension of Princeps' indulgentia giving individual treatment to each community and the spread of urban models. These interventions would become evident in the second century following the designation of the curatores. An evaluation of the known evidence shows that the status of conventual city did not determine its relationship with the emperor, for better or for worse.

\section{Key words:}

Emperor, indulgentia, epigraphic habit, iconography, Hispania. 
En las fuentes que se ocupan de la antigua Hispania apenas queda constancia de la presencia de los emperadores en las ciudades romanas de la Península Ibéricaํ. De hecho, el conjunto de las noticias para los dos primeros siglos del Principado es un magro repertorio que incluye, en primer lugar, la presencia de Augusto en Tarraco durante su segundo viaje a Hispania en 27/25 a. C. ${ }^{2}$ y, seguramente, más adelante en el año 15 a. C. ${ }^{3}$, la estancia de Galba en Clunia el año 68 a. C. en los meses previos a su proclamación imperial ${ }^{4}$ y, por último, el viaje de Adriano también a Tarraco en el invierno del 122/123 d.C. A ello habría que unir las

1. Este trabajo se ha realizado en el marco del proyecto de investigación HAR2015-65168-P de la Secretaría de Estado de Investigación, Desarrollo e Innovación del Gobierno de España. Agradezco a los organizadores de esta reunión sobre «Las ciudades del poder en Hispania» su amable invitación para presentar aquí este texto.

2. Dio 53.22.5 (27 a. C.). El viaje tenía por objeto asumir personalmente la dirección de la guerra en el norte peninsular contra Cántabros y Astures. Cf. R. Syme, “The Spanish War of Augustus”, American Journal of Philology, 55, 1934, 293-317 (traducción española: “La guerra de Augusto en Hispania”, Sautuola, 2, 1976-77, 303-316); A. Brancati, "Augusto e la guerra di Spagna”, Studi Urbinati, 26, 1952, 97 ss.; A. Rodríguez Colmenero, Augusto e Hispania. Conquista y organización del norte peninsular, Bilbao 1979, 112-128. Por el mismo Dión (Dio 53.25.7) sabemos que Augusto, aquejado por la enfermedad, hubo de retirarse en el año 26 a. C. a Tarraco, la ciudad que ya había visitado en el año 45 a. C., donde había asumido previamente in absentia el VIII consulado (26 a. C.) y donde ejercería el IX (25 a. C.); al respecto, cf. los detalles en G. Alföldy, "Das neue Edikt des Augustus aus El Bierzo in Hispanien”, ZPE, 131, 2000, 184; la datación de los consulados se puede seguir en D. Kienast, Römische Kaisertabelle. Grundzüge einer römischen Kaiserchronologie, 2a ed., Darmstadt 1996, 383-384 y 360. Antes del regreso a Roma en el primer semestre del año 24 a. C., ocuparía desde el 1 de enero el consulado X (Kienast, op. cit., 65).

3. J. M. Abascal, "Los tres viajes de Augusto a Hispania y su relación con la promoción jurídica de ciudades", Iberia, 9, 2006 [2009], 65-66.

4. Tac., Hist. 1.4.2-3; cf. G. Alföldy, Fasti Hispanienses. Senatorische Reichsbeamte und Offiziere in den spanischen Provinzen des römischen Reiches von Augustus bis Diokletian, Wiesbaden 1969, 16; E. W. Haley, "Clunia, Galba and the Events of 68-69“, ZPE, 91, 1992, 159-164; R. Syme, "Partisans of Galba", Historia, 31, 1982, 460-483. El viaje de Galba a Clunia, pese a que antecede ya a la proclamación imperial y que se vincula al oráculo local que apoyaría esa entronización, aún debía formar parte de los viajes habituales de un gobernador de la Citerior. En todo caso, la estancia en Carthago Nova en marzo del año 68 (Suet., Galba, 
escasas noticias sobre las relaciones de las ciudades con la central imperial. Pese a todo, este conjunto de evidencias seguiría careciendo de la relevancia suficiente como para vincular la vida de las ciudades - y específicamente la de las capitales conventuales- a la figura imperial. En el siglo III d.C., diría Herodiano que «Roma está donde está el Emperador»" esa circunstancia se dio bien pocas veces en los enclaves urbanos de la Península Ibérica. En un balance apriorístico se podría concluir que apenas hubo intervención imperial directa en las ciudades de Hispania y que, más que de intervención, habría que hablar de influencia, de eco de la actividad imperial y, más exactamente, de una presencia in absentia como veremos a continuación. Sin embargo, todo esto debe ser matizado.

Si hablamos de intervención imperial en los conventos jurídicos de Hispania, la primera observación que hay que realizar se refiere a la autoría de la propia estructura conventual en sí misma. Hoy en día casi nadie duda de que esta organización territorial debe fecharse en época augustea, de la misma manera que las ciudades que ejercieron la capitalidad administrativa tuvieron ese papel desde el principio. Llegar a esta conclusión no ha sido una tarea fácil para la investigación histórica; entre la centenaria propuesta de Eugène Albertini, que situó su temprano origen en la Baetica en la primera mitad del siglo I de la $\mathrm{Era}^{6}$, y la cronología flavia supuesta por científicos como Robert Étienne ${ }^{7}$ o Alain Tranoy ${ }^{8}$ y mantenida en sus más antiguos trabajos por Patrick Le Roux ${ }^{9}$ - quien luego aceptó la datación augustea ${ }^{10}$-, ha discurrido un caudal bibliográfico intenso cuyo punto central fue en su día la publicación de la Tabula Lougeiorum por parte de M. ${ }^{a}$ Dolores Dopico ${ }^{11}$, más tarde la magnífica síntesis

9-11; Plut., Galba, 4; Tac., Hist. 1.16.2.) claramente debe inscribirse en el contexto de esas visitas ordinarias del gobernador provincial.

5. Herod., Hist. 1.6.5. Cf. los comentarios para Tarraco de G. Alföldy, Tarraco y el Imperio romano, Discurso leído en la investidura como Doctor honoris causa en la Universitat Autònoma de Barcelona, Barcelona 1988, 20.

6. E. Albertini, Les divisions administratives de l' Espagne romaine, Paris 1923, 83.

7. R. Étienne, Le culte impérial dans la Péninsule Ibérique d’Auguste à Dioclétien, Paris $1974^{2}$ (1958), 188189.

8. A. Tranoy, La Galice romaine. Recherches sur le Nord-ouest de la Péninsule Ibérique dans l'antiquité, Paris 1981, 150-153.

9. P. Le Roux, L'armée romaine et l'organisation des provinces ibériques d'Auguste à l' invasion de 409, Paris 1982, 100; ID., "L' armée romaine dans la Péninsule Ibérique sous l' Empire: bilan pour une décennie", REA, 94, 1992, 239-240.

10. P. Le Roux, "La question des conventus dans la Péninsule Ibérique d'époque romaine", en $A u$ Jardin des Hespérides. Histoire, société et épigraphie des mondes anciens. Mélanges offerts à Alain Tranoy, Rennes 2004, 337-356, especialmente 355.

11. M. ${ }^{a}$ D. Dopico, La Tabula Lougeiorum. Estudios sobre la implantación romana en Hispania (Anejos de Veleia 5), Vitoria 1988. Imprescindible, de la misma autora, "Los conventus iuridici. Origen, cronología y naturaleza histórica", Gerión, 4, 1986, 265-283. Sobre el modelo de organización conventual véase también el trabajo de R. Haensch, "Zur Konventsordnung in Aegyptus und den übrigen Provinzen des römischen Reiches", en B. Kramer et. alii, Akten des 21. Internationalen Papyrologenkongresses. Berlin 13-19.8.1995, Stuttgart-Leipzig 1997, vol. 1, 320-391; ID., Capita provinciarum. Statthaltersitze und Provinzialverwaltung in der römischen Kaiserzeit, Mainz am Rhein 1997, 18-36. 
sobre la organización conventual a cargo de Pablo Ozcáriz ${ }^{12}$ y en la actualidad la revisión de la lectura y datación de algunas inscripciones de Saguntum y Tarraco por parte de Géza Alföldy, a quien se deben los últimos estudios sobre la cronología ${ }^{13}$.

En segundo lugar, es necesario recordar - como hizo Mierse hace unos años- que la presencia de Augusto en las ciudades quedó permanentemente asegurada a través del patronato directo, el establecimiento de lugares de culto, y la aparición de su imagen en las monedas y en la estatuaria ${ }^{14}$, lo que incluía el rediseño de ciudades que debían servir como capitales provinciales y conventuales ${ }^{15}$. De hecho, la extensión del retrato oficial del Príncipe en las monedas ${ }^{16}$ debe entenderse en ese contexto de difusión de una iconografía común que sirviera para crear referencias visuales de la figura del monarca y para aglutinar en torno al emperador a las élites dirigentes de las ciudades (Figura 1).

En este contexto de creación de una iconografía común hay que incluir el eco que tuvo en las ciudades de Hispania el desarrollo de la trayectoria institucional de Augusto, que fue narrada en las titulaturas imperiales que ocasionalmente conservamos en epígrafes pero, sobre todo, en las leyendas monetarias.
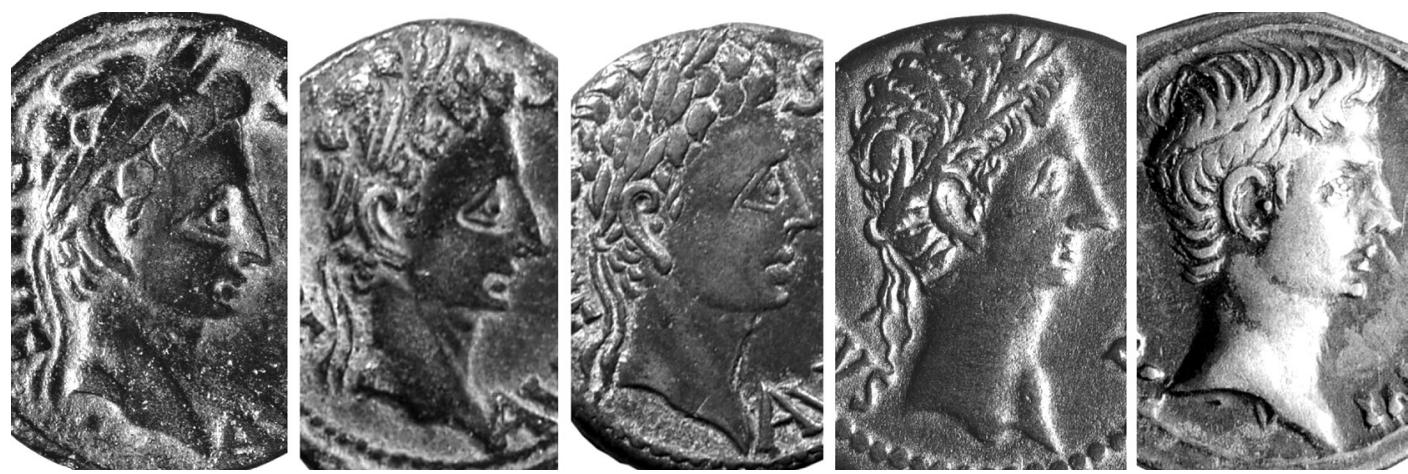

Figura 1. De izquierda a derecha: retrato de Augusto en monedas de Ilici, Carthago Nova, Celsa, Caesaraugusta y Augusta Emerita. Fotos: J. M. Abascal y P. P. Ripollès.

12. P. Ozcáriz, Los conventus de la Hispania citerior, Madrid 2006; ID., "Divisiones administrativas conventuales y realidades etno-territoriales”, en J. Santos Yanguas, G. Cruz Andreotti (Eds.), Revisiones de Historia Antigua VII. Romanización, fronteras y etnias en la Roma antigua: el caso hispano, Vitoria 2012, 559-579.

13. G. Alföldy, "Fasti und Verwaltung der hispanischen Provinzen: zum heutigen Stand der Forschung", en R. Haensch y J. Heinrichs (Eds.), Herrschen und Verwalten. Der Alltag der römischen Administration in der Hohen Kaiserzeit, Köln 2007, 325-356, especialmente 333-338, con toda la bibliografía anterior.

14. W. Mierse, "Augustan Building Programs in the Western Provinces", en K.A. Raaflaub y M. Toher (Eds.), Between Republic and Empire. Interpretations of Augustus and His Principate, University of California Press, Berkeley 1990, 308-333, especialmente 309.

15. Mierse, loc. cit., 309-310.

16. Mierse, loc. cit., 322. 
Más allá de la titulatura de anverso AVGVSTVS DIVI F que caracteriza la mayor parte de las emisiones monetarias hispano-romanas de este período de gobierno, algunas cecas particularizaron las leyendas con la introducción de elementos de esa titulatura imperial. Tarraco emitió con la inscripción IMP CAES AVG TR POT PON MAX P P; en algunas monedas de Osca se lee AVGVSTVS DIVI F PONT MAX PATER PATRIAI o AVGVSTVS PATER PATRIAI (sic); en Caesaraugusta las piezas del año 6 a. C. dicen AVGVSTVS DIVI F COS XI DES XII PONT MAX y las del $4 / 3$ a. C. dicen IMP AVGVSTVS (DIVI F) TRIB POTES XX; en Celsa se lee IMP CAESAR DIVI F AVGVSTVS COS XII; en Bilbilis se ve el texto AVGVSTVS DIVI F PATER PATRIAE, en Calagurris IMP AVGVST PATER PATRIAE o IMP CAESAR AVGVSTVS P P y en Turiaso y Calagurris IMP AVGVSTVS PATER PATRIAE ${ }^{17}$. En época augustea se trató de un fenómeno restringido a la capital de la Citerior y a determinadas zonas del valle del Ebro y sus proximidades; sin embargo, en tiempos de Tiberio esa práctica de incluir elementos de la titulatura imperial se reconocería en algunas de las cecas ya citadas y, además, en las de Clunia, Ebusus, Augusta Emerita, Carthago Nova, Ilici y Segobriga ${ }^{18}$. Esta última fue la única ceca en la que se precisó el número de las aclamaciones imperiales del sucesor de Augusto ${ }^{19}$.

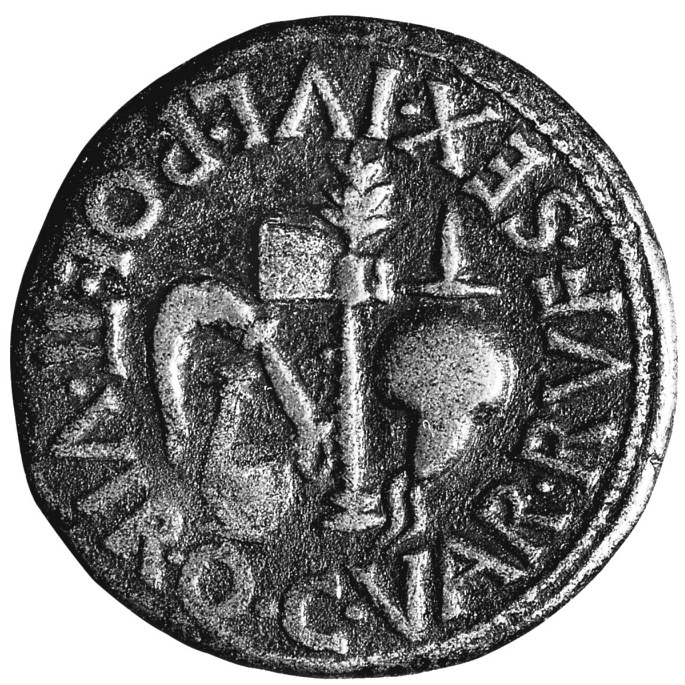

Figura 2. Reverso de un as de la ceca de Carthago Nova a nombre de Augusto, con representación de los atributos pontificales. Foto: P. P. Ripollès.

17. Los ejemplos citados y sus variantes están listados en P. P. Ripollès, Las acuñaciones provinciales romanas de Hispania, Madrid 2010, 308-309.

18. Ripollès, op. cit., 310-311.

19. A. Vives, La moneda hispánica, Real Academia de la Historia, Madrid 1924, n. ${ }^{\circ}$ CXXXV, 5; P. P. Ripollès, en A. Burnett, M. Amandry y P. P. Ripollès, Roman Provincial Coinage, vol. I, British Museum, London Paris 1992, n. 473-475; P. P. Ripollès y J. M. Abascal, Las monedas de la ciudad romana de Segobriga (Saelices, Cuenca), Barcelona - Madrid 1996, 128-153, series IVa-IVb; Ripollès, loc. cit., 2010, 288. 
No menos importante es el eco iconográfico de los cambios institucionales en Roma y en el entorno del emperador. Tras la muerte de Lépido el año 12 a. C., Augusto asumió el pontificado máximo y con ello obtuvo el derecho a ser representado con los atributos propios de este rango. El eco monetario en Hispania de ese relevo se encuentra en una moneda de Carthago Nova en cuya decoración del reverso se reconocen precisamente un simpulum, un aspergillum, un hacha y el apex o casquete propio de los sacerdotes ${ }^{20}$, es decir, los atributos pontificales (Figura 2). Esta particularidad de las emisiones locales es uno de los argumentos que apoyarían la tesis de que Augusto fuera patrono de esta importante colonia del sudeste peninsular ${ }^{21}$, máxime si tenemos en cuenta que estuvo allí con César durante el retorno de la batalla de $M u n d a^{22}$ y que la antigua colonia pompeyana ${ }^{23}$ debió entrar por entonces en el ámbito de sus clientelas. En este contexto de vinculación entre las ciudades de Hispania y la tradición romana, representada por el emperador, hay que interpretar las imágenes monetarias con ceremonias fundacionales, es decir, aquéllas en las que aparece el pontífice con la yunta de bueyes trazando el sulcus primigenius para el pomerium, que se reconocen en las monedas de Augusta Emerita y Caesaraugusta ${ }^{24}$.

Esa presencia iconográfica de Augusto a inicios del Principado debió ser decisiva para el fortalecimiento del culto imperial a comienzos del gobierno de Tiberio. Tenemos diversas evidencias de esa devoción por la figura imperial antes de la muerte del Princeps en agosto del año $14 \mathrm{~d}$. C. ${ }^{25}$. En el mundo oriental, al amparo de la autorización del propio Augusto para que se levantaron templos en su honor ${ }^{26}$ los habitantes de Mitilene, en la isla de Lesbos, erigieron uno que ya estaba concluido en los meses en que Augusto residió en Tarraco durante las Guerras Cántabras; la iniciativa incluía el establecimiento de un sacerdocio y de un calendario festivo específico, como sabemos por el decreto ${ }^{27}$ que la ciudad

20. Ripollès, loc. cit., 1992, n. ${ }^{\circ}$ 167-168 (RPC 167-168); Ripollès, op. cit., 2010, p. 130, no 167-168.

21. Mierse, loc. cit., 311.

22. Nic. Dam., de vita Aug. 11.12 (Jakoby). Dio 43.41.3 confirma esta participación del futuro Augusto en las últimas campañas cesarianas. Cf. Abascal, loc. cit., 2006, 64.

23. Cf. Abascal, "La fecha de la promoción colonial de Carthago Nova y sus repercusiones edilicias", Mastia, 1, 2002, 21-44, en donde se hace una recapitulación de los puntos de vista de la bibliografía anterior. La hipótesis de la fundación pompeyana ha sido avalada por las evidencias descubiertas después para Saguntum (P. P. Ripollès y J. Velaza, “Saguntum, colonia latina”, ZPE, 141, 2002, 285-291).

24. Mierse, loc. cit., 310. Los tipos monetarios pueden verse en Ripollès, loc. cit., 1992, no 5-7, 11, 15 (Augusta Emerita) y 304-310, 314, 317-318, 320, 322, 325-326, 333, 349-351, 371-372, 374-375, 381-382 y 386 (Caesaraugusta).

25. Para este tema es fundamental el relato de J. Ruiz de Arbulo, "El altar y el templo de Augusto en la colonia Tarraco. Estado de la cuestión”, en J. M. Noguera (Ed.), Paisaje urbano, arquitectura, programas decorativos y culto imperial en los foros de las ciudades hispanorromanas, Murcia 2009, 155-189, especialmente 169-171. Cf. también R. Mar y J. Ruiz de Arbulo, “Tribunal/Aedes Augusti. Algunos ejemplos hispanos de la introducción del culto imperial en las basílicas forenses", en Estudios sobre la Tabula Siarensis (Anejos de AEspA 9), Madrid 1988, 277-304; ID, "El foro de Ampurias y las transformaciones augusteas de los foros de la Tarraconense”, en W. Trillmich, P. Zanker. (Ed.), Stadtbild und Ideologie. Die Monumentalisierung hispanischer Städte zwischen Republik und Kaiserzeit (Madrid 1987), Munich 1990, 145-164.

26. Dio 51.20 .

27. Inscriptiones Graecae ad res Romanas pertinentes, 1929, IV 39. 
envió a Pérgamo, Brundisium o Actium y por el sentido de la embajada que el propio Augusto recibió en Tarraco entre 26 y 25 a. C. ${ }^{28}$. En occidente, en el año 12 a. C. Druso había dedicado cerca de Lugdunum, en la confluencia del Ródano y el Saona, el altar de las Tres Galias (Ara Romae et Augusti ad confluentes Araris et Rhodani) y entre los años 8 y $5 \mathrm{~d}$. C. se construyó el Ara Ubiorum de la Colonia Agrippinensis (Köln, Alemania) ${ }^{29}$. Pero no todo fueron expresiones colectivas de divinización del emperador; baste recordar el monumento consagrado entre los años 5 y 4 a. C. en Alcácer do Sal (Setúbal) por Vicanus Bouti $f($ ilius), en el que la titulatura de Augusto - al que se invoca como Imperatori Caesari Divi $f\left(\right.$ ilio) Augusto pontifici maxumo co(n)s(uli) XII trib(unicia) potestate XVIII ${ }^{30}$ - va seguida expresamente por la voz sacrum que, inequívocamente, indica que nos encontramos ante una dedicación de ámbito religioso y no ante un texto honorífico. No obstante, habrían de transcurrir aún casi dos décadas para que se autorizara oficialmente la instauración del culto imperial en la Península Ibérica, hecho señalado por la petición de los hispanos para construir el templo del Divus Augustus de Tarraco ${ }^{31}$.

Pero además de los ecos dinásticos evidenciados en los comportamientos de las élites y en la imagen pública de las ciudad, además de las expresiones de devoción inducidas por la necesidad de articular una relación directa entre el emperador y los ciudadanos de las provincias, la figura imperial fue haciéndose omnipresente en el funcionamiento diario de las comunidades, bien a través de órdenes ejecutivas conocidas por la epigrafía, o bien a través de intervenciones indirectas que se reflejan en los hábitos diarios de las comunidades y de las élites que las dirigían. El fenómeno es visible desde época de Augusto y sería una realidad también durante los gobiernos de sus sucesores.

28. R. Étienne, op. cit., 366; G. W. Bowersock, Augustus and the Greek World, Oxford 1965, 36-37.

29. Tac. Ann. 1.39. Sobre esta serie de construcciones y su relación interna, vid. Mierse, loc. cit., 323.

30. CIL II 5182, cf. p. 1029 (= ILER 1026). Sobre el texto véase J. d' Encarnação, Inscrições romanas do conventus Pacensis, Coimbra 1984, n 184; J. M. García, Religiões antigas de Portugal. Aditamentos e observações ás Religiões da Lusitânia de J. Leite de Vasconcelos. Fontes epigráficas, Lisboa 1991, n 476. Para la datación de la titulatura del emperador en el epígrafe, cf. Kienast, op. cit., 65-66.

31. Templum ut in colonia Tarraconensi strueretur Augusto petentibus Hispanis permissum, datumque in omnes provincias exemplum (Tac. Ann. 1.78.1); Cf. G. Converse Fiske, "Notes on the Worship of the Roman Emperors in Spain", Harvard Studies in Classical Philology, 11, 1900, 101-139; D. Fishwick, "The «Temple of Augustus" at Tarraco", Latomus, 58, 1999, 121-138; S. Panzram, Stadbild und Elite: Tarraco, Corduba und Augusta Emerita zwischen Republik und Spätantike, Stuttgart 2002, 33-35; J. Ruiz de Arbulo, "Bauliche Inszenierung und literarische Stilisierung: das 'Provinzialforum' von Tarraco”, en S. Panzram (Ed.), Städte im Wandel. Bauliche Inszenierung und literarische Stilisierung lokaler Eliten auf der Iberischen Halbinsel. Akten des Internationalen Kolloquiums des Arbeitsbereiches für Alte Geschichte des Historischen Seminars der Universität Hamburg und des Seminars für Klassiche Archäologie der Universität Trier im Warburg-Haus, Hamburg, 20.-22. Oktober 2005, Hamburg 2007, 149-212, especialmente 170-175; G. Pacci, “Tiberio e il culto imperiale”, en L. Gasperini y G. Pacci (Eds.), Nuove ricerche sul culto imperiale in Italia, Tivoli 2008, 193-197; J. Ruiz de Arbulo, op. cit., 2009, 179-183; R. Mar, J. Ruiz de Arbulo, D. Vivó y J. A. Beltrán-Caballero, Tarraco. Arquitectura y urbanismo de una capital provincial romana, vol. I. De la Tarragona ibérica a la construcción del templo de Augusto, Tarragona 2012, 348-371. 
Una de esas tempranas manifestaciones en Hispania es el llamado bidental de Bracara Augusta, es decir la ceremonia expiatoria conducente a borrar el recuerdo de un rayo caído sobre la tierra o sobre un árbol mediante un ritual expiatorio ${ }^{32}$. En sentido estricto, un bidental es el monumento construido en el lugar en que cayó el rayo y recibe su denominación del sacrificio de una oveja de dos años o bidens ${ }^{33}$. Del ritual y del monumento que pudo tener lugar en Bracara Augusta sólo nos ha quedado un bloque con inscripción que se encuentra empotrado en uno de los muros exteriores de la catedral de Braga ${ }^{34}$. El epígrafe, conocido desde el siglo XVI, fue visto por E. Hübner en julio o agosto de $1861^{35} \mathrm{y}$, sobre el calco que éste obtuvo, construyó Th. Mommsen los suplementos que luego aparecerían en la edición de CIL II. El texto con esos suplementos fue recogido por Montero y Perea, que publicaron hace unos años un dibujo en el que modificaron, por necesidades de paginación, la abreviatura final del último verso (Figura 3).

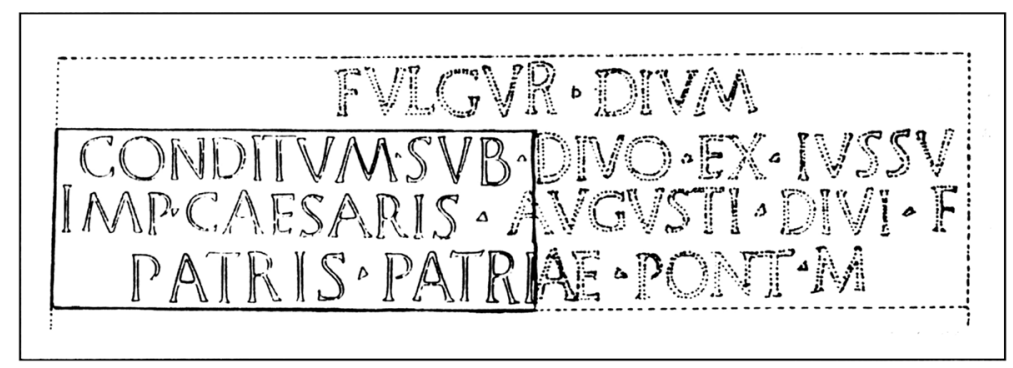

Figura 3. Inscripción conmemorativa del bidental de Bracara Augusta en un sillar empotrado en los muros exteriores de la catedral de Braga. Dibujo de S. Montero y S. Perea sobre hipótesis de lectura de Th. Mommsen a partir del calco de Hübner.

32. S. Montero y S. Perea, "Augusto y el bidental de Bracara (ad CIL II 2421)", en J. M. ${ }^{a}$ Blázquez y J. Alvar (Eds.), La romanización en Occidente, Madrid 1996, 299-315, que hablan acertadamente de un ritual para «enterrar un rayo».

33. Sobre la identidad del bidens y con la bibliografía anterior, cf. Montero y Perea, loc. cit., 301.

34. CIL II 2421; cf. p XLIV y 900; J. J. Rigaud de Sousa, Subsidios para a carta arqueológica de Braga (Studia archaeologica 23), Valladolid-Santander 1973, 23; A. Tranoy, "Religion et societé à Bracara Augusta (Braga) au Haut-Empire romain", en Actas do Seminario de Arqueología do noroeste peninsular, Guimarães 1980, vol. 3, 70 no 1 con fotografía; J. M. García, op. cit., no 478; Montero y Perea, loc. cit., 299-300 (HEp 7, 1997, 1162), con mucha más bibliografía; M. Horster, Bauinschriften römischer Kaiser. Untersuchungen zu Inschriftenpraxis und Bautätigkeit in Städten des westlichen Imperium Romanum in der Zeit des Prinzipats, Stuttgart 2001, 363.

35. No podemos precisar la cronología debido a que el viaje de Hübner por el norte de Portugal se prolongó entre el 4 de julio y los primeros días de agosto de ese año (cf. J. M. Abascal, "Hübner y el Corpus Inscriptionum Latinarum II", Iberia Archaeologica, e.p.). De ese viaje hay una crónica del propio Hübner en su "Epigraphische Reiseberichte aus Spanien und Portugal", Monatsberichte der Königlichen Preuss. Akademie der Wissenschaften zu Berlin 1861, 1862, 16-113 (VI. Granada, Jaén, Córdoba, Sevilla), 378-405 (VII. Extremadura), 525-549 (VIII. Sin título), 721-771 (IX. Lissabon und das südliche Portugal), 771-807 (XII. Portugal nördlich von Tajo), 807-837 (XIII. Galicien, Leon, Asturien) y 938-986 (XIV. Altkastilien, die baskischen Provinzen, Navarra, Aragón, Catalonien und Menorca). Para el texto que nos ocupa, véase p. 792. 
A los efectos que ahora nos interesan, la construcción del texto no deja lugar a dudas sobre la presencia de la titulatura imperial en genitivo; ese extremo y la presencia de la voz conditum en el primer renglón conservado, aboca casi sin remedio a la solución propuesta por Mommsen con la forma ex iussu Imp. Caesaris; eso indica que nos encontramos ante un monumento construido sub divo, es decir, a cielo abierto, que fue erigido por orden imperial o mediante la intervención directa de alguno de los legados augusteos que visitaron la ciudad después del año 2 a. C., pues Augusto recibió ese año el título de pater patriae que se lee en el epígrafe.

Más de un siglo después, en Tarraco, volveremos a encontrarnos con la intervención imperial relacionada con un espacio religioso. Sabemos por la Historia Augusta que Adriano visitó la ciudad en el invierno de los años $122 / 123^{36}$ y que, con tal motivo, ordenó que se restaurara a sus expensas el templo de Augusto $^{37}$, es decir, el templo consagrado al Divus Augustus $^{38}$ que se había construido a comienzos del gobierno de Tiberio (vid. supra). De tal restauración hay una evidencia suficiente en el epígrafe erigido por aquellos años en honor de C. Calpurnius Flaccus, flamen provinciae Hispania citerioris, al que se denomina curator templi y praefectus murorum de la capital de la Citerior ${ }^{39} \mathrm{y}$ al que se debió encomendar la realización de las obras que el propio Adriano iba a financiar. En todo caso, no debe confundirse esta iniciativa llevada a cabo en el ámbito decisivo del ordo Tarraconensis con la de dorar las estatuas de Adriano que, probablemente, se encontraban en el espacio del foro provincial y que correspondían al ámbito de actuación del concilium provinciae ${ }^{40}$.

Desde época augustea, la intervención imperial en las ciudades se hizo patente también desde el punto de vista jurídico pues, mediante los numerosos edicta, decreta, mandata y rescripta que conocemos, hizo uso de esa capacidad normativa que le confería la ley ${ }^{41} \mathrm{y}$ de esta manera articuló un mecanismo de relación con las ciudades que se ha

36. Post haec Hispanias petit et Tarracone hiemavit, ubi sumptu suo aedem Augusti restituit. Omnibus Hispanis Tarraconem in conventus vocatis dilectumque ioculariter, ut verba ipsa ponit Marius Maximus, retractantibus Italicis vehementissime, ceteris prudenter caute $<q u e>$ consuluit. Sobre el viaje de Adriano a Tarraco (HA, H 12.3-5); cf. H. Halfmann, Itinera principum. Geschichte und Typologie der Kaiserreisen im Römischen Reich (HABES 2), Stuttgart 1986, 190; A. R. Birley, Hadrian, the restless emperor, London - New York 1997, 146-148 ; G. Alföldy, "Hadrians Besuch in Tarraco (HA, H 12, 3-5)", en Historiae Augustae Colloquium nanceiense. Atti dei Convegni sulla Historia Augusta XII, Edipuglia, Bari 2014.

37. HA, H. 12.3 .

38. Sobre el edificio afectado por las obras de C. Calpurnius Flaccus, cf. D. Fishwick, "Four Tempels at Tarraco", en A. M. Small (Ed.), Subject and Ruler: The Cult of the Ruling Power in Classical Antiquity. Papers presented at a conference held in The University of Alberta on April 13-15, 1994, to celebrate the $65^{\text {th }}$ anniversary of Duncan Fishwick (JRA Suppl. 17), 1996, 172; J. S. Richardson, The Romans in Spain, Massachusetts 1996, 222.

39. Alföldy CIL II²/14, 1124 (= CIL II 4202; Dessau ILS 6946), con mucha más bibliografía y amplios comentarios sobre el viaje de Augusto y su influencia en la ciudad.

40. Sobre la inscripción que da a conocer esa actuación véase Alföldy CIL II²/14, 1154 (= CIL II 4230; Dessau ILS 6930), con más bibliografía y la explicación de las diferencias entre las dos iniciativas.

41. L. Pietanza, Indulgentia: virtù e strumento amministrativo del Principe, Bari 2010, 19. Véase, además, R. Orestano, "Gli editti imperiali. Contributo alla teoria della loro validità ed efficacia nel diritto romano 
definido como de «petición y respuesta»; es decir, el emperador intervenía mediante la emisión de esos instrumentos jurídicos citados cuando previamente las ciudades habían solicitado su participación ${ }^{42}$ para resolver un litigio, para aliviar la presión fiscal, para condonar una deuda, etc. ${ }^{43}$; casi siempre, esas solicitudes se canalizaban mediante el envío de embajadas ${ }^{44}$. Las actuaciones jurídicas derivadas de esas peticiones constituían propiamente muestras de la indulgentia del soberano ${ }^{45}$. De esa indulgentia deja constancia una inscripción de Hispalis relacionada con el collegium centonariorum ${ }^{46}$. Entre los mejores ejemplos hispanos, ajenos al ámbito de las capitales conventuales, se cuenta la epístola de Vespasiano a Sabora en la que autorizaba la construcción de una ciudad en la llanura y en la que se hizo patente, de una parte, la indulgentia imperial y, de otra, el papel secundario que en la relación con las ciudades tenían los gobernadores ${ }^{47}$; a esa misma categoría de las demostraciones de indulgentia imperial como respuesta a una petición local pertenece también la carta de Tito a Munigua del 7 de septiembre del año $79^{48}$ o el cambio de régimen jurídico de Italica en tiempos de Adriano ${ }^{49}$.

classico", en Bullettino dell' Istituto di diritto romano, 44, 1936-37, 219-331; ID., Il potere normativo degli imperatori e le costituzioni imperiali, Torino 1937; F. Gallo, "El potere normativo imperiale", en Studia et documenta Historiae et Iuris, 48, 1982, 413-454.

42. La tesis fue defendida básicamente por F. Millar en su obra The Emperor in the Roman World (31 $B C-A D$ 337), London $1983^{2}$; véase al respecto, J. Bleicken, Zum Regierungsstil des römischen Kaisers: eine Antwort auf Fergus Millar, Wiesbaden 1982. Un punto de vista actual sobre el impacto de esa tesis en la historiografía más reciente puede verse en E. Lo Cascio, "Introduzione", en A. Storchi Marino y G. D. Merola (Eds.), Interventi imperiali in campo económico e sociale. Da Augusto al tardoantico, Bari 2009, 5-11. Cf. W. Eck, "Der Kaiser, die Führungsschichten und die Administration des Reiches (von Vespasian bis zum Ende der antoninischen Dynastie)", en Die Verwaltung des römischen Reiches in der Hohen Kaiserzeit. Ausgewählte und erweiterte Beiträge, vol. 2, Basel 1998, 3-145.

43. Sobre el mecanismo de "petición y respuesta» véase especialmente T. Hauken, Petition and Response: an epigraphic study of petitions to Roman Emperors 181-249, Monographs from the Norwegian Institute at Athens, Bergen 1998, con mucha más bibliografía.

44. Sobre un tema tan amplio y que requeriría una atención pormenorizada, véase Millar, op. cit., 375-385.

45. Pietanza, op. cit., passim.

46. J. Campos y J. González, "Los foros de Hispalis colonia Romula", AEspA, 60, 1987, 133-135 n. ${ }^{\circ}$ II, fig. 8 (AE 1987, 496; HEp 3, 1991, 354); J. González Fernández, Corpus de inscripciones latinas de Andalucía, vol. II: Sevilla. Tomo I. La Vega (Hispalis), Sevilla 1991, 20-22 no 7 (HEp. 4, 1994, 805).

47. CIL II 1423 y pp. 867 y 1049 (Dessau ILS 6092), de Cañete la Real (Málaga); A. D’ Ors, Epigrafía jurídica de la España romana, Madrid 1953, 61-63, nº 4; J. González Fernández, Bronces jurídicos romanos de Andalucía, Sevilla 1990, 167-168 n. ${ }^{\circ}$ 12. Sobre el documento, véase además F. Jacques, Les cités de l'Occident romain, Paris 2004, 147-148, n 78; N. Barrandon, "Le Sénat, les gouverneurs et les citès pérégrines d' Hispanie romaine", en N. Barrandon y F. Kirbihler (Ed.), Les gouverneurs et les provinciaux sous la République romaine, Rennes 2011, 127-128.

48. AE 1962, 288; J. González, op. cit., 1990, n. ${ }^{\circ} 13$.

49. Gell. Noct. Att. 16.13.4-5. R. Syme, "Hadrian and Italica", JRS, 54, 1964, $142-149$ (= Roman Papers II, Oxford 1979, 617-628). 


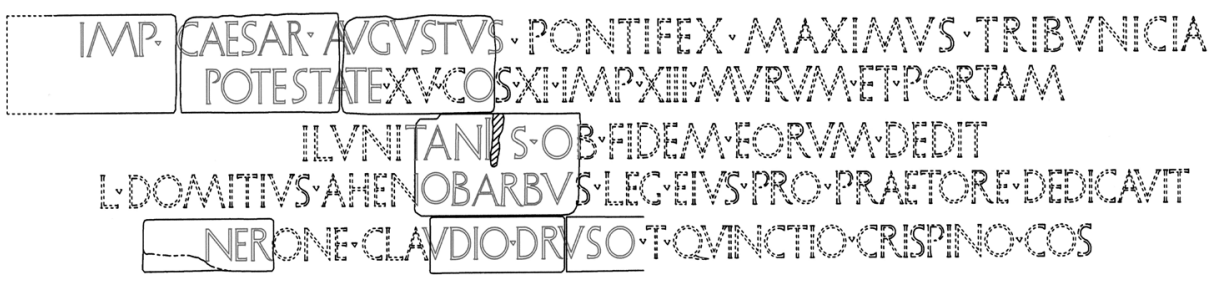

Figura 4. Inscripción monumental de El Tolmo de Minateda (cercanías de Hellín, Albacete, Hispania citerior), según la reconstrucción propuesta y editada por G. Alföldy. Dibujo de J. M. Abascal y B. Ruck.

Desde el gobierno de Augusto la intervención imperial en el urbanismo de las ciudades se fue haciendo notar tanto de manera directa — mediante la promoción de determinadas obras públicas y de infraestructura hidráulica ${ }^{50}$ - como indirecta, mediante el consentimiento para que los núcleos urbanos se dotaran de infraestructuras presididas por inscripciones con la titulatura imperial. En el primer caso, desde la central imperial se impulsaron a lo largo del Principado multitud de obras públicas que pudieron ser subvencionadas por la caja del Estado mediante cualquier mecanismo fiscal compensatorio, y que serían ejecutadas por medio de los gobernadores provinciales en tanto agentes del emperador en todas las provincias ${ }^{51}$. Entre los ejemplos hispanos que deben formar parte de esa relación se encuentran los tres epígrafes de las tribunas del anfiteatro $^{52}$ de Augusta Emerita y los fragmentos de un epígrafe que quizá contuviera la titulatura de Adriano en esa misma ciudad ${ }^{53}$. A la relación hay que añadir un epígrafe de Pax Iulia (Beja),

50. J. M. Abascal y U. Espinosa, La ciudad hispano-romana: privilegio y poder, Logroño 1989, 199; E. Melchor Gil, “Aquam in municipium perduxerunt: epigrafía y construcción de obras hidráulicas en la Hispania romana”, en S. Gómez Navarro (Coord.), El agua a través de la Historia, Córdoba 2004, 35-48.

51. En las últimas décadas se han publicado varias obras que abordan esta cuestión en diferentes momentos y en diversos territorios: G. Waldherr, Kaiserliche Baupolitik in Nordafrika. Studien zu den Bauinschriften der diokletianischen Zeit und ihre räumliche Verteilung in den römischen Provinzen Nordafrikas, Frankfurt an Main 1989; E. Wuinter, Staatliche Baupolitik und Baufürsorge in den römischen Provinzen des kaiserzeitlichen Kleinasien, Bonn 1996; M. Horster, Literarische Zeugnisse kaiserlicher Bautätigkeit, Stuttgart 1997; A. Scheithauer, Kaiserliche Bautätigkeit in Rom. Das Echo der antiken Literatur, Stuttgart 2000; M. Horster, op. cit., 191-198, con un tratamiento detenido del tema. Sobre esta última obra, véase la detenida reseña y los comentarios de G. Alföldy en JRA, 15, 2002, 489-498.

52. AE 1959, 28 y HAE 1479. J. L. Ramírez Sádaba, "Epigrafía del anfiteatro romano de Mérida”, en Bimilenario del anfiteatro romano de Mérida. Coloquio internacional 'El anfiteatro en la Hispania romana' Mérida 26-28 de noviembre 1992, Mérida 1994, 293; ID., Catálogo de las inscripciones imperiales de Augusta Emerita, Mérida 2003, pp. 38-41, n. ${ }^{9}$ 9-11 (HEp 13, 2003-2004, 109); cf. Horster, op. cit., 2001, 348-349, que entiende, pienso que adecuadamente, que el sentido de los tres textos indica que el emperador dedit las obras a que se refieren los epígrafes.

53. CIL II 478a-k (Horster, op. cit., 2001, 350-351); cf. EE 8, p.361s. y EE 9, p. 25. Es sabido que, pese a los intentos de Hübner de componer con todos ellos un solo epígrafe, tal hipótesis no está ni mucho menos 
datado en la primera mitad del año 2 a. C., según el cual el emperador Augusto habría dado a esta colonia y capital conventual [muros] turres e[t p] inscripción colocada en un lugar visible de alguna de estas construcciones ${ }^{54}$.

Ese mismo sentido parece tener el texto grabado sobre el conjunto de sillares que formaron parte de la muralla de la ciudad asentada en el lugar conocido como Tolmo de Minateda, en las cercanías de Hellín (Albacete), en las regiones centrales del conventus Carthaginiensis. Aunque el derrumbe de la muralla dio al traste con algunos de los bloques, parte de los cuales fueron reutilizados en construcciones cercanas, subsiste aún un número suficiente de ellos como para permitir la restitución del texto que propuso hace unos años G. Alföldy (Figura 4) $)^{55}$. Según ese documento, el emperador Augusto Ilulitanis ob fidem eorum dedit es decir, dio a los ilunitanos en agradecimiento por su fides, por su apoyo a la causa romana en las décadas inmediatamente anteriores- una obra pública que sería la muralla en sí misma, construida con cargo al erario público romano. La fecha de esa construcción no plantea ninguna dificultad puesto que, además de los restos de la titulatura imperial con la decimoquinta potestad tribunicia del monarca, el texto contiene una datación consular con los nombres de Nero Claudius Drusus y Titus Quinctius Crispinus, es decir, los cónsules del año 9 a. C. Es cierto que este enclave no era una capital conventual; sin embargo, hay que tener en cuenta que las enormes dimensiones del conventus Carthaginiensis provocaron que no sólo Carthago Nova como capital, sino otras ciudades dispersas por el territorio, se vieran beneficiadas de los apoyos directos de la casa imperial. El hallazgo de la inscripción sirvió también para conocer el nombre del gobernador provincial de ese año, Cn. Domitius Ahenobarbus, que aparece en el epígrafe seguramente como el legado que se responsabilizó directamente de los trabajos ${ }^{56}$. Sin ánimo de ser exhaustivos, en el ámbito de las capitales conventuales de Hispania, habría que citar también el complejo texto de Clunia con la titulatura de Galba, debido

aceptada. Cf. Ramírez Sádaba, loc. cit., 2003, 76-82 n. ${ }^{\circ}$ 37-46, que no vincula entre sí los fragmentos como hiciera Hübner; J. C. Saquete, "Materiales epigráficos procedentes del área del gran templo de culto imperial de Augusta Emerita: una revisión necesaria", Habis, 36, 2005, 277-297, especialmente p. 289 y nota 43 ( $A E$ 2005, 760); A. U. Stylow, "La epigrafía y el culto imperial en Augusta Emerita: nuevos epígrafes del conjunto provincial del culto imperia", en El foro provincial de Augusta Emerita: un conjunto monumental de culto imperial (Anejos de AEspA 42), Madrid, 2006, 297-314, especialmente 299-304 (AE 2006, 582).

54. J. d' Encarnação, "Inscrição monumental de Pax Iulia", Ficheiro Epigráfico, 29, 1988, n. ${ }^{\circ} 131$ (AE 1989, 368; HEp 2, 1990, 744); ID., op. cit., 1984, n. ${ }^{\circ} 292$. Cf. M. Horster, op. cit., 352.

55. Sobre los fragmentos de la inscripción del Tolmo de Minateda, véase L. Abad, "La epigrafía del Tolmo de Minateda (Hellín, Albacete) y un nuevo municipio romano del conventus Carthaginensis", AEspA, 69, 1996, 100-102 (AE 1996, 907a; HEp 6, 1996, 14) y la interpretación general del contenido en G. Alföldy, op. cit., 2007, 340-341, Taf. XVIII (HEp 16, 2007, 2).

56. Sobre este personaje, véase Groag, PIR ${ }^{2}$ D 128; B. E. Thomasson, Laterculi praesidum I, Göteborg, 1984, col. 88, n. ${ }^{\circ} 7$ y col. 371-372, n. ${ }^{\circ}$; R. Syme, La revolución romana, Madrid 1989, 475, 476, 496, 502, 503, 528, 532, 533 y 637; ID., L’aristocrazia augustea, Milán 1993, 456 y 629; J. Fitz, Die Verwaltung Pannoniens in der Romerzeit I, Budapest 1993, 57, n. ${ }^{\circ}$; J. M. Abascal, "Lucius Domitius Ahenobarbus", en Diccionario Biográfico de la Real Academia de la Historia vol. 16, Madrid 2011, 543-544; cf. Alföldy, loc. cit., 2007, 340341. 
a que el título imperial aparece en nominativo ${ }^{57}$, un supuesto epígrafe de Caesaraugusta que ya Hübner catalogó entre los falsos ${ }^{58}$ y, cómo no, el epígrafe más largo del Imperio Romano, aquél que - grabado en 79 bloques que formaban la corona del púlpito del anfiteatro de $\mathrm{Ta}$ rraco - relataba la restauración llevada a cabo por Heliogábalo en el año $221^{59}$.

En algunas de estas construcciones, los epígrafes fueron formados con litterae aureae o auratae, como las denomina un epígrafe de Peñaflor (Sevilla) ${ }^{60} \mathrm{y}$, sobre todo, con letras de bronce convenientemente pulidas para asegurar su brillo. Esta técnica - de la que el testimonio más antiguo se encuentra en la inscripción original del año 30 a. C. en el obelisco situado frente a la Basílica de San Pedro en Roma ${ }^{61}$ - tuvo una especial importancia a partir del año 17 a. C. que fue, según la ideología del principado augusteo, el año del nacimiento de esa nueva aurea aetas en la que las litterae aureae llegaron a ser un medio de expresar una parte de la ideología del nuevo orden de Roma. La técnica se extendería desde entonces a las provincias y el año 16 a. C. ya se empleó en la puerta augustea de la colonia de Nemausus (Nîmes) en la Gallia Narbonensis ${ }^{62}$ y en el teatro de Augusta Emerita, inaugurado en este mismo año como una donación de Agrippa ${ }^{63}$. El empleo reiterado de las litterae aureae fue un eco directo de la arquitectura de la propia ciudad de Roma y, por lo tanto, de los programas decorativos que narraban el discurso político del gobierno de Augusto, por lo que llegó a representar una forma de mostrar la fidelidad de las ciudades de las provincias a esa forma de dirigir el Estado y a todo lo que representaba. Es decir, del uso de esta técnica sólo se puede hacer una lectura política: las ciudades de provincias - y también las de Hispania - asumieron en sus hábitos epigráficos oficiales las pautas de la propia Roma y con ello las élites locales de cada uno de esos núcleos dieron una muestra más de su lealtad. Esta técnica epigráfica se emplearía tam-

57. CIL II 2779. P. de Palol y J. Vilella, Clunia II. La epigrafía de Clunia (Excavaciones arqueológicas en España 209), Madrid 1987, no 213. Cf. Horster, op. cit., 358.

58. CIL II 255*; cf. ahora M. Navarro Caballero, “Agrippa et Caesaraugusta: relecture”, Epigraphica, 64, 2002, 29-56 (AE 2002, 799; HEp 12, 2002, 550), que propone rehabilitar este documento.

59. Alföldy $C I L \mathrm{II}^{2} / 14,921$ con toda la bibliografía anterior y un larguísimo estudio. Véase ahora, en castellano, G. Alföldy, Las inscripciones monumentales del anfiteatro de Tarraco, Tarragona 2012, con la traducción de la obra original (G. Alföldy, Die Bauinschriften des Aquäduktes von Segovia und des Amphitheaters von Tarraco. Mit einem Anhang von Peter Witte (Madrider Forschungen 19), Berlin - New York 1997) y un prólogo del autor.

60. AE 1975, 503; AE 1976, 281; J. Remesal, “De topografía y epigrafía celtitana”, en Celti (Peñaflor). La arqueología de una ciudad hispanorromana en la Baetica: Prospecciones y excavaciones 1987-1992, Sevilla 2001, 184-185, n. ${ }^{\circ}$ 16: D. M. s.; Atimeti lib., Fabia Merope, annorum LXXV pia in suis/ h. s. e. s. t. t. l. si quantum pietas potuit tantum fortuna dedisset litteris auratis scribere hunc titulum.

61. G. Alföldy, Der Obelisk auf dem Petersplatz in Rom. Ein historisches Monument der Antike, Sitz.-Ber. d. Heidelberger Akad. d. Wiss., Phil.-hist. Kl., Jg. 1990, Bericht 2, Heidelberg 1990, especialmente 21-27, con la bibliografía anterior; sobre la fecha de la inscripción vid. 33-37.

62. CIL XII 3151.

63. CIL II 474 (Dessau ILS 130); J. R. Mélida, Catálogo monumental, Provincia de Badajoz, Madrid 1925, 142 s.; I. Di Stefano Manzella, Mestiere di epigrafista. Guida alla schedatura del materiale epigrafico lapidario (Vetera 1), Roma 1987, 182. 
bién para las pavimentaciones forenses, aunque sólo en un foro de capital conventual en Hispania, el de Carthago Nova ${ }^{64}$, tenemos atestiguado el uso de este tipo de inscripciones, que se encuentran también en Saguntum ${ }^{65}$, Segobriga ${ }^{66}$ y en Torreparedones (Ituci?) ${ }^{67}$.

Respecto a la intervención urbanística inducida, un buen ejemplo sería también el caso de Carthago Nova, donde la marmorización de los edificios públicos — con materiales frecuentemente importados de canteras imperiales como las de Luni-Carrara- da a entender que estos programas edilicios fueron llevados a cabo por gentes próximas a los círculos imperiales $^{68}$. En las tierras del interior de Hispania se podría aducir el ejemplo del arco de Medinaceli, en cuyo coronamiento septentrional se leía Numini Augusto sacrum, seguido de un texto hoy perdido; en la fachada meridional, el monumento albergaba una inscripción formada con litterae aureae y la titulatura de Domiciano, sustituida luego por la de Trajano después del año $98 \mathrm{dC}$. y tras la damnatio memoriae del último de los Flavios ${ }^{69}$. Es cierto que no se trata de una sede conventual aunque, por la distancia a la capital y su papel estratégico, se convirtió en un centro neurálgico de su territorio.

En todo caso, las remodelaciones urbanísticas de todas las sedes conventuales, como las del resto de ciudades, se llevarían siempre a cabo tomando como modelo las prácticas desarrolladas en la propia Roma, en donde la arquitectura —-desde tiempos de Augusto — se había adaptado a

64. J. M. Noguera, J. M. Abascal, “Fragmentos de epígrafes e inscripción con litterae aureae del foro y del Augusteum de Carthago Nova”, Mastia, 2, 2003, 11-63, especialmente 53-68; J. M. Abascal, J. M. Noguera, $\mathrm{M}^{\mathrm{a}}$ J. Madrid, "Nuevas inscripciones romanas de Carthago Nova (Cartagena, Hispania Citerior)", ZPE, 182, 2012, 287-290, especialmente 291-294.

65. G. Alföldy, Los Baebii de Saguntum, Valencia 1977, 7-13 y 43-49; ID., CIL II²/14, 374, con el resto de la bibliografía.

66. J. M. Abascal, G. Alföldy, R. Cebrián, "La inscripción con letras de bronce y otros documentos epigráficos del foro de Segobriga", AEspA, 74, 2001, 117-130.

67. J. A. Morena, A. Ventura y C. Márquez, "El foro de la ciudad romana de Torreparedones (Córdoba): primeros resultados de la investigación arqueológica (campaña 2009-2010)", Italica, 1, 2011, 145-169, especialmente 160-162 (HEp 18, 2009, 117). A. Ventura Villanueva, J. A. Morena López, "Una arquitectura definida: la inscripción pavimental con litterae aureae y el foro de la colonia bética Virtus Iulia Ituci (Torreparedones, Baena, provincia de Córdoba)", en R. Robert (dir.), Dire l'architecture dans l'Antiquité, Marseille Paris 2016, 411-448

68. B. Soler Huertas, "El uso de los mármoles en los programas decorativos de la Carthago Nova altoimperial: edilicia pública y evergetismo", en La decoración arquitectónica en la ciudades romanas de Occidente, Murcia, 2004, 455-483, especialmente 472. Sobre la marmorización de esta ciudad véase ahora J. M. Noguera, M. ${ }^{a}$ J. Madrid, "Mármoles y marmorización arquitectónica en Nova Carthago: nuevas evidencias del Molinete", en V. García-Entero (Ed.), El marmol en Hispania: explotación, uso y difusión en época romana, Madrid 2012, 229-252.

69. G. Alföldy, J. M. Abascal, "La inscripción del arco", en EID. (Eds.), El arco romano de Medinaceli (Soria, Hispania Citerior), Madrid 2002, 71-115 (AE 2002, 796). Cf. J. M. Abascal, "El arco de Medinaceli", en M. Criado de Val (Ed.), Atlas de caminería hispánica. Vol. 1: Caminería peninsular y del Mediterráneo, Madrid 2011, 46-49. 
la representación espacial del discurso político y a la explicación en imágenes de la ideología imperial $^{70}$. Esas réplicas locales de la arquitectura oficial son fáciles de seguir en los modelos locales ${ }^{71}$.

Algunas ciudades y capitales conventuales tendrían un especial protagonismo en determinados momentos del Principado: Augusta Emerita y Caesaraugusta, después de su fundación, debieron ser desarrolladas por los ingenieros militares y la caja imperial; Clunia fue sede del oráculo empleado por el círculo provincial contrario a Nerón para proclamar a Galba el año $68^{72}$, el lugar en que se reveló el arcanum Imperii ${ }^{73}$; Italica alteró su régimen jurídico en tiempos de Adriano $^{74}$ y fue monumentalizada y reurbanizada por él ${ }^{75}$; hacia el año 215 dC., el senador romano y gobernador de la Bética Caecilius Aemilianus consultó el oráculo del templo de Heraklés de Gades, lo que le supuso la ejecución por orden de Caracala, y con esa evidencia terminan nuestras noticias sobre el funcionamiento del Herakleion gaditano ${ }^{76}$. Por razones debidas a su posición estratégica y a su intensa actividad administrativa, estamos mejor informados de la situación en Tarraco que en otros centros urbanos. Como sede del gobernador de la mayor provincia del Imperio, Tarraco alcanzó un enorme protagonismo político ${ }^{77}$ y experimentó un desarrollo urbanístico extraordinario ${ }^{78}$. De allí procede, por

70. P. Zanker, Augusto y el poder de las imágenes, Madrid 1992.

71. J. Ruiz de Arbulo (Ed.), Simulacra Romae I. Roma y las capitales provinciales del occidente europeo. Estudios arqueológicos, Tarragona 2004; R. González Villaescusa y J. Ruiz de Arbulo (Eds.), Simulacra Romae II. Rome, les capitales de province (capita prouinciarum) et la création d'un espace commun européen. Une approche archéologique, Actes du colloque tenu à Reims les 19, 20 et 21 novembre 2008 édités par la Société Archéologique Champenoise, Reims 2010.

72. Tac., Hist. 1.4.2-3.

73. Tac., Hist. 1.4.2.

74. Gell. Noct. Att. 16, 13.4-5. Cf. nota 49.

75. Dio 69.10, 1. Abascal, Espinosa, op. cit., 199.

76. Dio 77.20.4; J. Ma Blázquez, "El Herakleion gaditano, un templo semita en Occidente", en Actas del I Congreso Arqueológico del Marruecos español. Tetuán 1953, Tetuán 1955, 317-318; A. García y Bellido, "Hércules Gaditanus", AEspA, 36, no 107-108, 1963, 128. Sobre el personaje, cf. Groag, PIR² C 16; G. Barbieri, L'albo senatorio da Settimio Severo a Carino (193-285), Roma 1952, 27, n. ${ }^{\circ}$ 93; G. Alföldy, Fasti Hispanienses. Senatorische Reichsbeamte und Offiziere in den spanischen Provinzen des römischen Reiches von Augustus bis Diokletian, Wiesbaden 1969, 173; ID., "Der Status der Provinz Baetica um die Mitte des 3. Jahrhunderts”, en R. Frei Stolba y M.A. Speidel (Eds.), Römische Inschriften-Neufunde,Neulesungen und Neuinterpretationen. Festschrift für Hans Lieb zum 65. Geburstag dargebrachjt von seinen Freunden und Kollegen, Basilea 1995, 37; F.J. Navarro, "El proconsulado de la Bética en el cursus honorum senatorial”, Gerión, 22, 2004,387 y 395-396.

77. G. Alföldy, «Tarraco», RE, suppl. 15, 1978, col. 569-643. (ed. castellana: Tarraco, Forum, Temes d'història i d'arqueologia tarragonines 8, Tarragona 1991); J. Ruiz de Arbulo, “Tarraco, Carthago Nova y el problema de la capitalidad en la Hispania citerior republicana”, en Miscel.lània arqueològica a Josep M. Recasens, Tarragona 1992, 115-130; G. Alföldy, “Introducción histórica”, en X. Dupré (Ed.), Las capitales provinciales de Hispania 3. Tarragona, Colonia Iulia Urbs Triumphalis Tarraco, Roma 2004, 7-155; R. Mar y J. Ruiz de Arbulo, “Tarragona romana: República i Alt Imperi (anys 218 a. C. - 265 d. C.)”, en Historia de Tarragona, Tarragona 2010, 207-538.

78. Sobre el desarrollo urbano véase J. Ruiz de Arbulo, loc. cit., 2007, 149-212; Mar, Ruiz de Arbulo, Vivó y Beltrán-Caballero, op. cit., 2012, passim, con mucha más bibliografía, que constituye el primer volumen de una obra que incluirá también la arquitectura de etapas posteriores a la augustea.

Revista de Historiografía 25, 2016, pp. 405-421 
ejemplo, la inscripción que conmemora el nombramiento como gobernador de la Citerior de Ti. Claudius Candidus, dux terra marique adversus rebelles hh(ostes) pp(ublicos) tras la derrota de los partidarios de Clodio Albino en Lugdunum el 19 de febrero de 197 dC. ${ }^{79}$.

En todo caso, la evidencia más tangible de la intervención imperial en la vida de las principales ciudades de Hispania llegaría a partir del gobierno de Marco Aurelio, momento al que pertenecen sendos epígrafes de Hispalis y Arva ${ }^{80}$ que revelan la presencia en ambos núcleos de los primeros curatores $^{81}$, es decir, de los primeros agentes imperiales enviados a las ciudades con capacidad para interferir en su autonomía económica y administrativa; esta situación se prolongaría en el tiempo, pues la mayor parte de los testimonios disponibles de curatores corresponden a los siglos III y IV dC. Al mismo período pertenece la oratio de Marco Aurelio y Cómodo sobre el precio de los gladiadores ${ }^{82}$, que constituyen la evidencia de las normativas especiales que poco a poco fueron socavando la autonomía local desde la central imperial. Si esa autonomía se prolongó en el tiempo sólo fue debido a que la ciudad era un instrumento imprescindible para la administración del Imperio y a que, fundamentalmente, sobre sus decuriones y ciudadanos recaía la carga económica que hacía funcionar esa maquinaria local y, como consecuencia de ello, la del Imperio.

Cuando se sopesan todos los testimonios mostrados en las páginas precedentes y el resto de los conocidos, se hace evidente que la condición de capital conventual no fue determinante para que cada ciudad gozara de una mayor o menor relación con el Princeps. Por el contrario, más allá del obligado protagonismo de las capitales provinciales, especialmente de Tarraco por su cercanía a Roma y por las dimensiones del territorio que gestionaba, da la impresión de que la posición geográfica o estratégica, el protagonismo económico o la fortaleza de las élites locales fueron factores mucho más determinantes en la historia de cada comunidad que la ocasional condición de sede conventual.

En cualquier caso, pese a que en apariencia hubo una escasa intervención del Estado y del emperador en la vida de las ciudades de Hispania, tanto mediante la extensión de la titulatura y de la iconografía imperiales, como a través del culto imperial, las directrices urbanísticas tácitas, el uso discrecional de la indulgentia imperial e, incluso, con la intervención directa de las haciendas locales a partir del siglo II dC., esa intervención fue constante, máxime si partimos del hecho de que el propio diseño de la estructura administrativa de los conventus fue una parte fundamental de la reorganización territorial del estado augusteo.

Para esa intervención prolongada en el tiempo, que mediatizó en gran medida la historia particular de cada comunidad, no fue preciso introducir modificaciones esta-

79. Alföldy CIL II $2 / 14,975$ (= II 4114; Dessau ILS 1140).

80. CIL II 6283 y 1180.

81. Abascal, Espinosa, op. cit., 1989, 216. Sobre los curatores urbanos, véanse G. P. Burton, "The curator rei publicae: towards a reappraisal, Chiron, 9, 1979, 465-487; G. Camodeca, "Ricerche sui curatores rei publicae", ANRW II.13, 1980, pp. 453-489; F. Jacques, Les curateurs des cités dans l'occident romain de Trajan à Gallien. Études prosopographiques, Paris 1983; ID., Le privilège de liberté. Politique impériale et autonomie municipale dans les cités de l' Occident romain, 161-244, Roma 1984, passim; E. Lo Cascio, Il Princeps e il suo Imperio. Studi di storia amministrativa e finanziaria romana, Bari 2000, 27-28.

82. CIL II 6278 (Dessau ILS 5163). D’ Ors, op. cit., 1953, 37-60, n. ${ }^{\circ} 3$. 
tutarias en las leyes locales ni dotar a cada población de un cuerpo jurídico adicional. Tanto la intervención directa como la inducción de determinadas pautas de comportamiento se hicieron al amparo de las relaciones ordinarias entre las ciudades y el Princeps, pues el propio sistema de organización del Imperio estaba diseñado para permitir la plena injerencia estatal en la vida local. 